\title{
How to detect \\ Obstructive Sleep Apnea \\ Syndrome (OSAS) in children
}

\author{
Thierry SEAILLES, Vincent COULOIGNER, \\ Julia COHEN-LÉVY
}

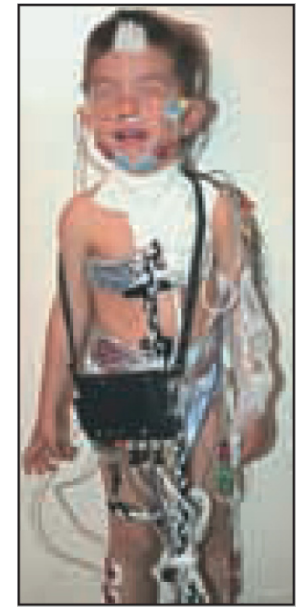

\begin{abstract}
Obstructive Sleep Apnea Syndrome (OSAS) is a frequently occurring childhood malady, whose is incidence is largely underestimated, that can lead to serious complications. Because of their understanding of the anatomy and physiology of the masticatory apparatus and of the upper airways, orthodontist are in a strategic position to detect in their young patients developing disorders in these regions; accordingly when they suspect the existence of OSAS they should ask systematic and well targeted questions of parents who may not be aware of the relationship between certain symptoms their children display and sleep breathing problems. The goal of this article is to provide practitioners with a better understanding of the symptoms and the physio-pathological mechanics of OSAS so that they can spare their afflicted patients the complications it provokes by seeing that early treatment is undertaken.
\end{abstract}

\section{KEYWORDS}

Obstructive sleep apnea syndrome

Children

Diagnosis

Polysomnography. 


\section{1 - INTRODUCTION}

Guilleminault ${ }^{42}$ first described the precise characteristics, that vary from individual to individual, of OSAS in 1976, noting that obstruction of the upper airways during sleep could be intermittent, partial, or complete. But actually, Osler ${ }^{75}$ and Hill ${ }^{46}$ first reported it 120 years ago in these terms: "the stupid and lazy child who suffers from headaches in school, breathes through his mouth rather than his nose, snores during his agitated sleep, and awakens with his mouth dry, deserves better treatment by the school nurse."

OSAS, which affects 1 to $4 \%$ of the child population ${ }^{61}$, can lead to serious disturbances in a child's bodily functions, with alterations in respiratory exchanges, repeated micro-awakenings, and a change in sleep patterns. It is associated with a multitude of complications most of which have only been identified in the last 10 years:

- a decrease in growth both in height and weight ${ }^{25,62}$, resulting from fragmentation of the profound deep sleep that, when undisturbed, promotes the release of growth hormones;

- problems in waking behavior ${ }^{1,2,8,}$ $10,16,19,20,30,31,34,44,49,52,53,54,68,70,72,73$,

76,83,88,93,94 with pseudo-hyperactivity and an increase in psychiatric problems;

- difficulties in concentration and learning, interference with control of functional activity with a lowered scores on intelligence tests, and difficulties in classroom performance. It should be noted that there is a 6 to 9 times greater risk of OSAS in the 3 lowest ranked students in the class ${ }^{34}$;

- sleepiness, which is rather rare, affecting only about $20 \%$ of OSAS patients ${ }^{33,66}$;

- early onset of cardio-vascular difficulties, primarily arterial hypertension, and changes in the dimensions of the cardiac chambers $4,5,6,23,24,40$, $56,57,58,63,98$.

- metabolic changes, which are the most recently identified complications ${ }^{55,82,86}$;

- problems in growth of the facial complex;

- an abundance of therapeutic interventions that double medical expenses before a diagnosis has been made 82,89 ;

- a major interference with the quality of life as measured objectively on specific questionnaires $21,27,29,67,71,85$.

\section{2 - EPIDEMIOLOGICAL RISK FACTORS FOR CHILDREN IN THE OBSTRUCTIVE SLEEP APNEA SYNDROME}

The prevalence of OSAS is estimated to be between 1 and $4 \%$ and as high as 5 , even $10 \%{ }^{92}$ in some studies, with a slight pre-ponderance of males near the age of puberty. Some observers note an increased rate of OSAS in certain ethnic groups, especially African populations.

That the familial factor is important is demonstrated by the 3 to 4 time higher risk children run of contracting 
sleep apnea if a family member suffers from it ${ }^{84}$. In children born prematurely the risk is multiplied by a factor of 3 to $5^{45,84}$

OSAS is also associated with other disorders such as asthma, ear, nose, and throat infections (recurring otitis, rhinitis, and sinusitis), obesity, drepanocytic anemia, and certain congenital afflictions such as trisomy 21 , neuromuscular problems, and maxillo-facial malformations.

\section{- Physio-pathology}

While obstruction of the upper airways, which is considerably encouraged or aggravated by physiological hypertrophy of tonsillar and adenoidal tissues that usually attain their maximum proliferation when children are 3 to 5 years old ${ }^{48}$, constitutes the principal causative factor in OSAS, it is not the sole inciting mechanism. OSAS, a complex manifestation, is also triggered by neuro-muscular activation of the upper airways, by malfunctions of breathing controls, and by mal-stimulation at the threshold of cerebral cortex activation.

Typical apnea mechanisms derive from varying degrees of obstruction of the upper airways and pharyngeal spaces in afflicted children compared to the free passageways of healthy infants, which is most clearly seen at times of awakening ${ }^{69}$, after sedation ${ }^{7}$, and with paralysis ${ }^{47}$. The narrowness of air passages can be discerned by means of cephalometrics ${ }^{9,71}$, acoustic rhino-manometrics ${ }^{69}$, endoscopy $^{47}$, and magnetic resonance imaging $^{7,22,28}$.

The collapse of airways is related to anatomical obstacles and also to changes in neuro-muscular activity that in healthy operation tend to prevent that collapse through the action of the dilating musculature of the pharynx, especially the génioglossus, the hypoglossus, and the styloglossus all of which help to regulate the inspiration of air ${ }^{50}$.

For children afflicted with OSAS the critical pressure tending to close the airways is higher than it is in healthy children; this increased possibility of collapse becomes evident after sedation or experimentally induced paralysis, and the site of the shrinkage is primarily in areas of adenoidal tissue excess, the soft palate, and the pharyngeal or hypo-pharyngeal space $^{7,28}$.

The respiratory anomalies caused by this breakdown in equilibrium of forces are extremely variable and range from increased effort in breathing, lowered intake of oxygen, rapid respiration and assorted anomalies of aeration exchange to complete obstruction ${ }^{35,41}$.

But despite everything, the upper airways of children with OSAS remain open most of the time, a testimonial to the importance of neuro-muscular control in diminishing their collapse. In OSAS, the structure of sleep may be affected as repeated cortical miniawakenings break it up and as the level of alternating cyclical tracings increases as measured on an electroencephalogram reading up to the beginning of subtle activations of the nervous system in the form of autonomic mini-awakenings $51,77,78,79,90$.

There is a continuum between "simple" snoring 38,44,72, which is an early indication of narrowing of the upper airways, the syndrome of augmentation of the upper airways 
described in 1982 by Guilleminault ${ }^{35}$, and the sleep apnea syndrome, the borderline between a physiological event and pathological blockage being difficult to determine.

With means and devices of evaluation, primarily polysomnography, be- coming increasingly sensitive $e^{15,17,37}$ $41,60,79,91$, many cases of "increased resistance in the upper airways syndrome" that would have escaped undetected only a few years ago, are now being diagnosed correctly.

\section{3 - SYMPTOMATOLOGY OF OSAS}

Usually, OSAS is first discerned through assessment of clinical symptoms ${ }^{97}$, a medical history, a morphological and functional evaluation of the upper airways, and finally by the indispensable polysomnographic examination, which, alone, can provide an irrefutable objective confirmation of the diagnosis ${ }^{37}$.

\section{3 - 1 - Nocturnal symptoms}

- Snoring a frequent manifestation of the onset of OSAS and could be considered a first call for help from both parents and medical care providers $^{45}$. Snoring occurs in $96 \%$ of OSAS cases ${ }^{14,39}$, but this high rate may reflect a selection bias; respiration that is merely noisy, or in some cases complete absence of snoring, can characterize some confirmed OSAS cases ${ }^{61}$.

On the other hand, epidemiological studies have found that 8 to $12 \%$ of all children display "regular snoring"61, showing that snoring is not associated solely with OSAS.

- Pauses in respiration or repeated noises in breathing have been noted by 1 to $4 \%$ of parents. These interruptions are more frequent just before morning during phases of paradoxical sleep, while slow deep sleep which predominates at the beginning of the evening is usually free of these respiratory pauses.

- Night sweats are a good indication of increase of the blood level of carbon dioxide and bear witness to the hypoventilation that accompanies apnea. They can occur daily and be abundant.

- Nocturnal mouth breathing (which is sometimes occurs in the daytime) reflects an obstruction in the nasal air passageways and the preferred route of air to reach the lungs; it implies a greater resistance to nasal air flow than to buccal air flow ${ }^{26}$. In healthy children, the resistance to passage of air through the mouth is greater than it is through the nose ${ }^{44}$ and $70 \%$ of inspired air, accordingly, takes the nasal route; but in children suffering from apnea mouth breathing is a protective mechanism that is a detour around the nasal obstacles.

\section{- Abnormal sleeping positions}

By setting their heads in a hyperextended position thus limiting lowering of the base of the tongue children can improve air flow ${ }^{95}$. Children also adopt this position when 
they nod off during long automobile trips; when they continue this behavior during waking moments it may become a chronic statural anomaly.

These parasomnias are encouraged by sleep interruptions due to cortical mini-awakenings that are more or less complete and repetitive. They result primarily from the breathing difficulties that afflict children with apnea whose sleep is agitated with frequent position changes, shaking of the lower limbs, night terrors, recurrent nightmares, confusion in waking periods, bruxism, episodes of somnambulism or somniloquy, repeated nocturnal arousals, nocturnal micturation or enuresis $^{51}$, and, with nursing infants, nocturnal crying.

\section{3 - 2 - Diurnal symptoms}

During the day as opposed to the behavior of healthy children, apneal patients show a continuance or a reappearance of excessive napping, for relatively long periods. Sometimes these involuntary siestas occur in situations that encourage them such as long trips or periods of passivity like television watching or even in classrooms.

These children tend to fall asleep rapidly at bedtime, but sometimes their dropping off is paradoxically retarded, especially for children who

\section{4 - THE CLINICAL EXAMINATION}

After the general physical examination, the complete measurement of height and weight, a calculation of the of the body mass index (BMI), an have been made anxious by frequent nightmares or poor quality of sleep.

In adolescents OSAS may provoke a reluctance to fall asleep demonstrated by later and later bedtimes. In the morning, their awakening is often prolonged and difficult; less often it is paradoxically early with the agitated children unable to fall asleep again. Some of the children suffer from morning headaches caused by a nighttime accumulation of excess of carbon dioxide in the blood stream.

In waking hours, most children with apnea demonstrate a pseudo-hyperactivity, appearing agitated, unable to concentrate or study at all, frequently encountering scholastic difficulties.

Some writers have reported episodes of passivity in these patients, causing them to be introverted or even depressed.

Detailed questionnaires, like the one devised by Brouillette ${ }^{13}$, have been adapted for the study of potential patients. They focus, as in the Epworth modification, on respiratory parameters and diurnal somnolence. Another instrument that has been employed is the Pediatric Sleep Questionnaire, the $\mathrm{PSO}^{18}$. While these questionnaires constitute a tool for evaluating OSAS, they cannot be used to affirm or eliminate the present of the obstructive sleep apnea syndrome.

exploration of the upper airways is made.

- In the nasal examination otolaryngologists look for asymmetry in the 


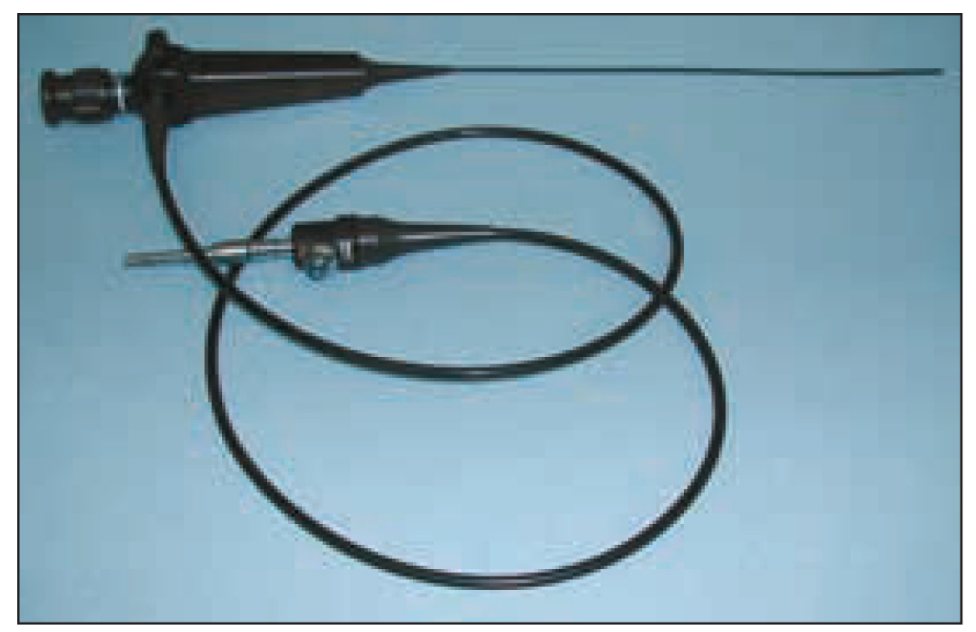

Figure 1

Nasofibroscopy (Dr J. Briffod, Paris). After administration of local anesthetic, a supple pediatric endoscope is introduced through the nose in order to assess the decrease in the caliber of the nasal airway. The nasal fibroscopy permits the examiner to analyze the nasal fossas, the choanae, the cavum, and the larynx.

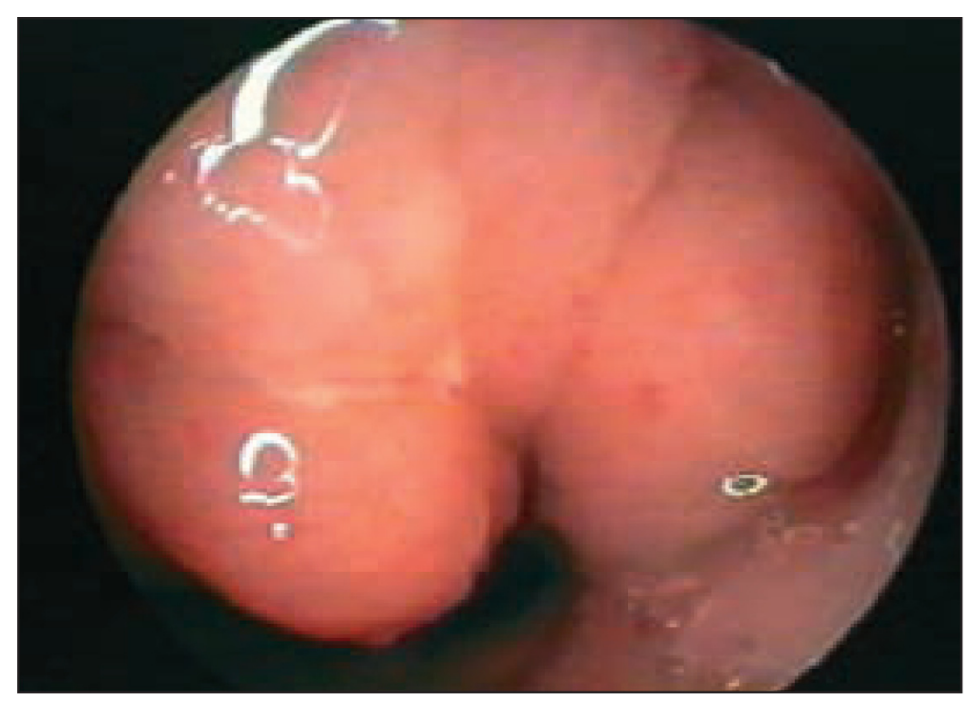

Figure 2

Hypertrophy of vegetations visible in the fibroscopy.

size of the nostrils, a large septum, partial or complete collapse of the nostrils (through the external nasal valve), a deviation of the septum, hypertrophy of the turbinates, and inflammation or infection of the mu- cosa, all of which could lead to impeded or obstructed air passages. They can conduct this examination, an anterior rhinoscopy, directly with the aid under high-powered scialytic light, and a speculum with a mobile valve. 


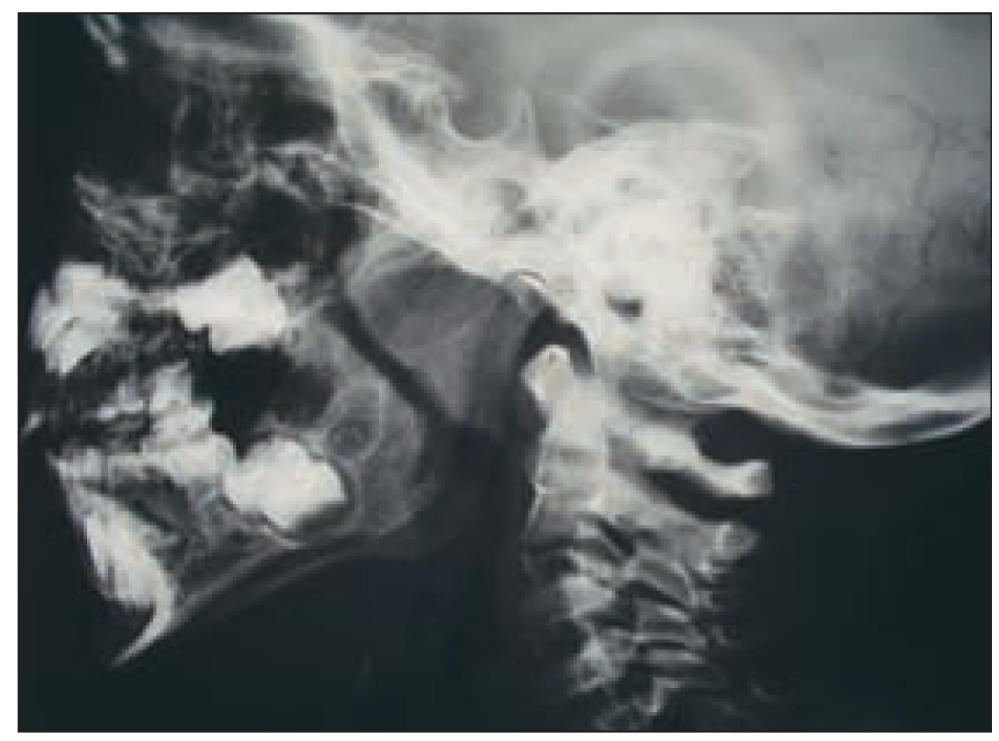

Figure 3

A radiograph of the cavum shows the hypertrophy of the vegetations of a 3 year old child.

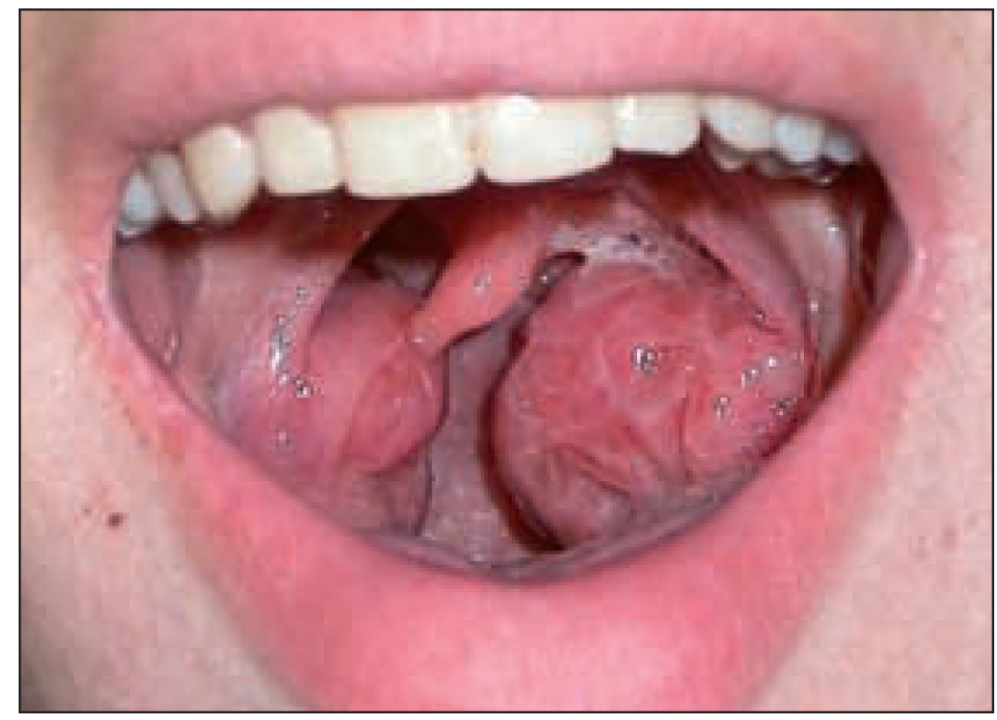

Figure 4

Hypertrophic palatal adenoids (Dr B. Pételle, Paris).

The otolaryngologists can complete the minute examination not only in the nasal area but also of the tubular orifices, the Eustachian tubes as well as the soft palate with a nasal fibro- scopy, carried out under local anesthesia with a vaso-constrictor that replaces the cumbersome posterior rhinoscopy with a mirror. In the case of the patient shown in figure 2 , an 


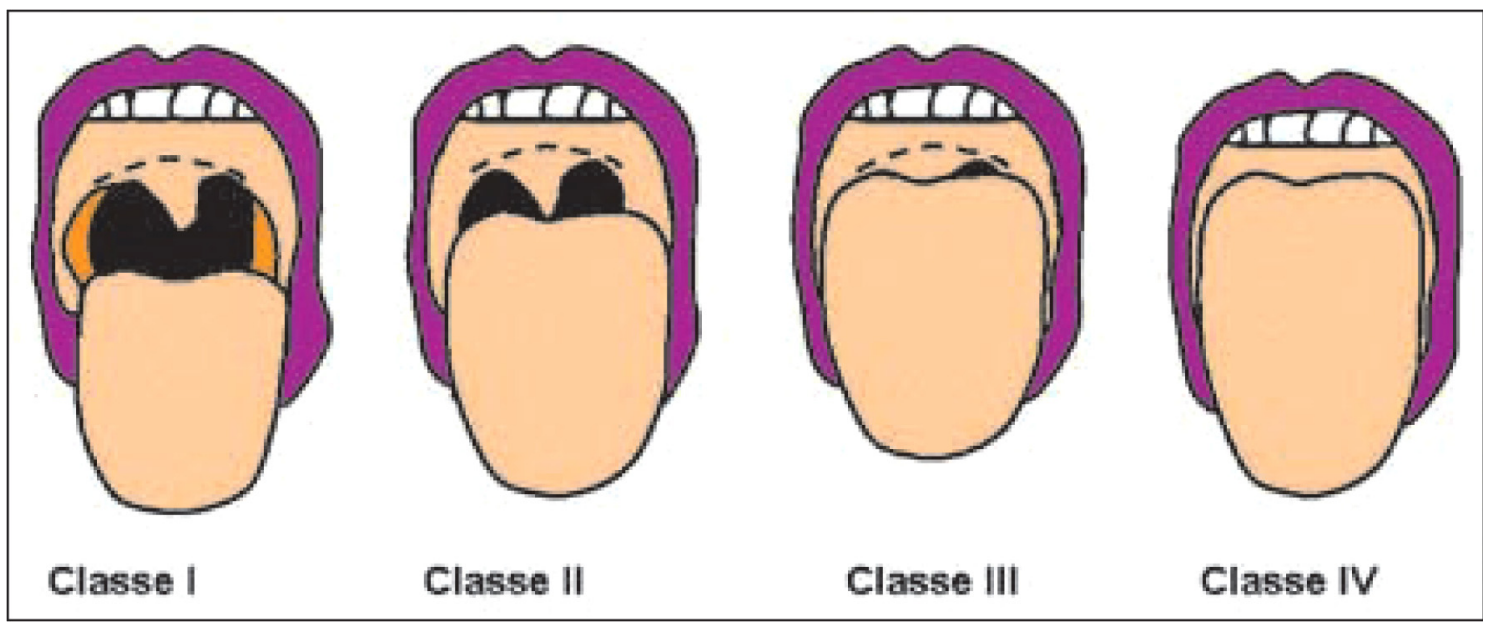

Figure 5

The Mallampati Score.

Utilized initially under anesthesia, the Mallampati score helps the examiner to analyze the anatomy of the oral cavity helping the examiner to predict the difficulty of oro-tracheal intubation. A score of 4 strongly indicates the presence of OSAS.

Class 1: the uvula in its entirety and the tonsillar pillars are visible.

Class 2: the palatal uvula is partially visible.

Class 3: the soft palate is visible.

Class 4: only the hard palate is visible.

X-Ray of the cavum clearly shows the hypertrophy of the adenoids.

- The position of the uvula in relation to tongue is assessed by a Mallampati score (figure 5), and the size of adenoids is rated in comparison to the volume of upper airway passage (figure 4). With other techniques, such as rhinometry or the measurement of nasal deficit, the

\section{5 - RECORDING SLEEP PATTERNS}

The symptoms we have described indicate the need for a polysomnographic evaluation, but they do not constitute sufficient evidence for making a diagnosis of OSAS nor for examiner can make an evaluation of respiratory function a routine of the OSAS exam.

- Over-all cranio-facial morphology, primarily of the mandible and the palatal vault, which is frequently high and narrow, is also assessed (the reader may wish to consult the article on OSAS morphology in this issue).

evaluating its severity ${ }^{11,18}$, because there is no correlation between the intensity of symptoms in an individual and the apnea-hypopnea index. A recording of sleep patterns is, 


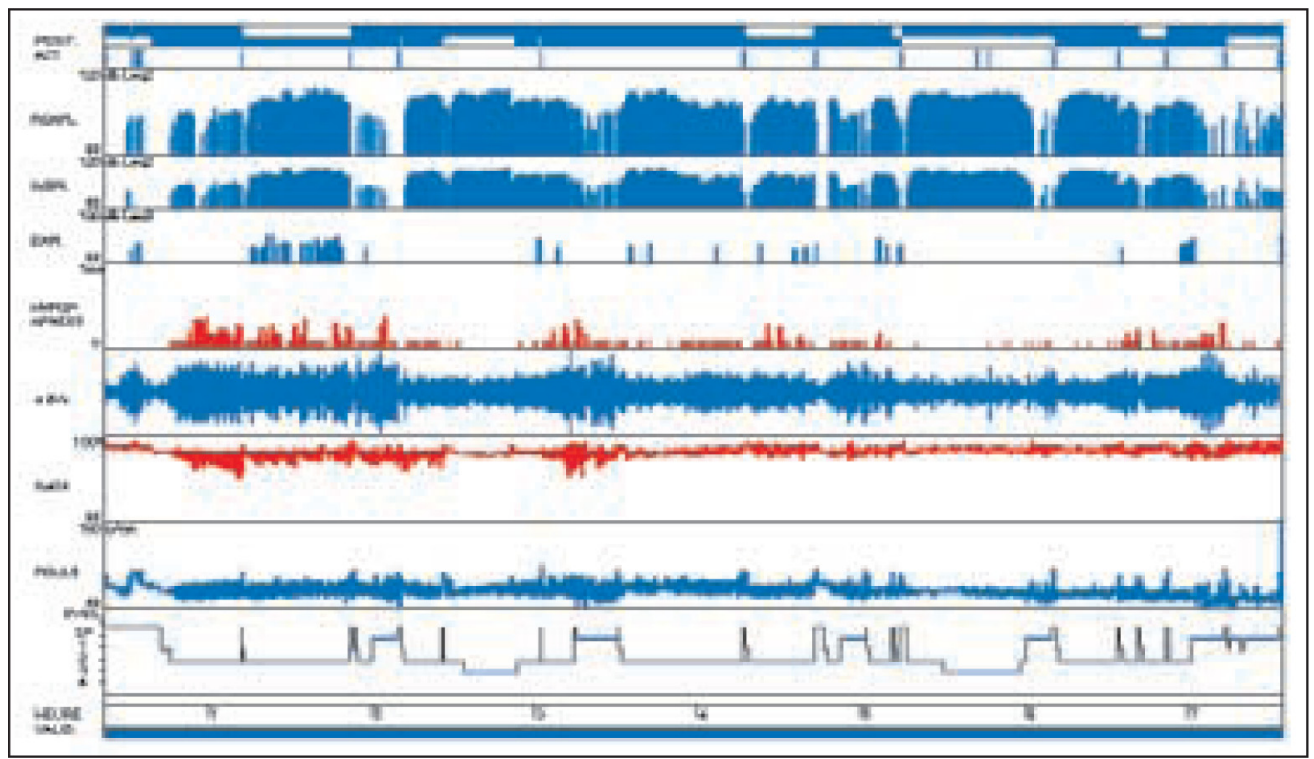

Figure 6

Resume of a polysomnograph, showing pathological tendencies.

Line 1: a position sensor discerns the specific abnormal respiratory events that occur most frequently when the patient is lying in a dorsal decubitus position.

Line 2: snoring, in Decibels, on inspiration or expiration.

Line 5: obstructive évents: hypopnea and apnea.

Line 7: Oxygen saturation.

Line 8: Pulse.

Line 9: Sleep stages I to IV, phases of paradoxal sleep.

therefore, the only objective means of confirming the presence of the obstructive sleep apnea syndrome. However, there is ongoing debate on the issue of how many sensors are needed to make a proper diagnosis of OSAS:

- oxymetrics, derived from a sensor placed on the patient's finger registers the blood oxygen level and aids in an index of respiratory interruptions that may lower it;

- the Ventilation polygraphy (VP), which measures cardio-respiratory parameters including Ventilation deficit, oxymetrics, and cardiac rate;

- the polysomnography, (PSG) which is a more profound, more exacting procedure often undertaken in a sleep laboratory. Patients frequently have to wait for it because of the restricted number of beds available in these facilities. The PSG makes registrations of different stages of sleep derived from electro-encephalographic graphs and an electrooculogram that discerns specific phases of arousal and sleep, notably REM, or Rapid Eye Movement, and also records changes in leg placement from a position sensor with electromyograms along with a night-long electrocardiogram (see fig. 6 and 7).

The respiratory parameters are evaluated with a nasal pressure sensor, an intra-oral thermistor, abdominal and 


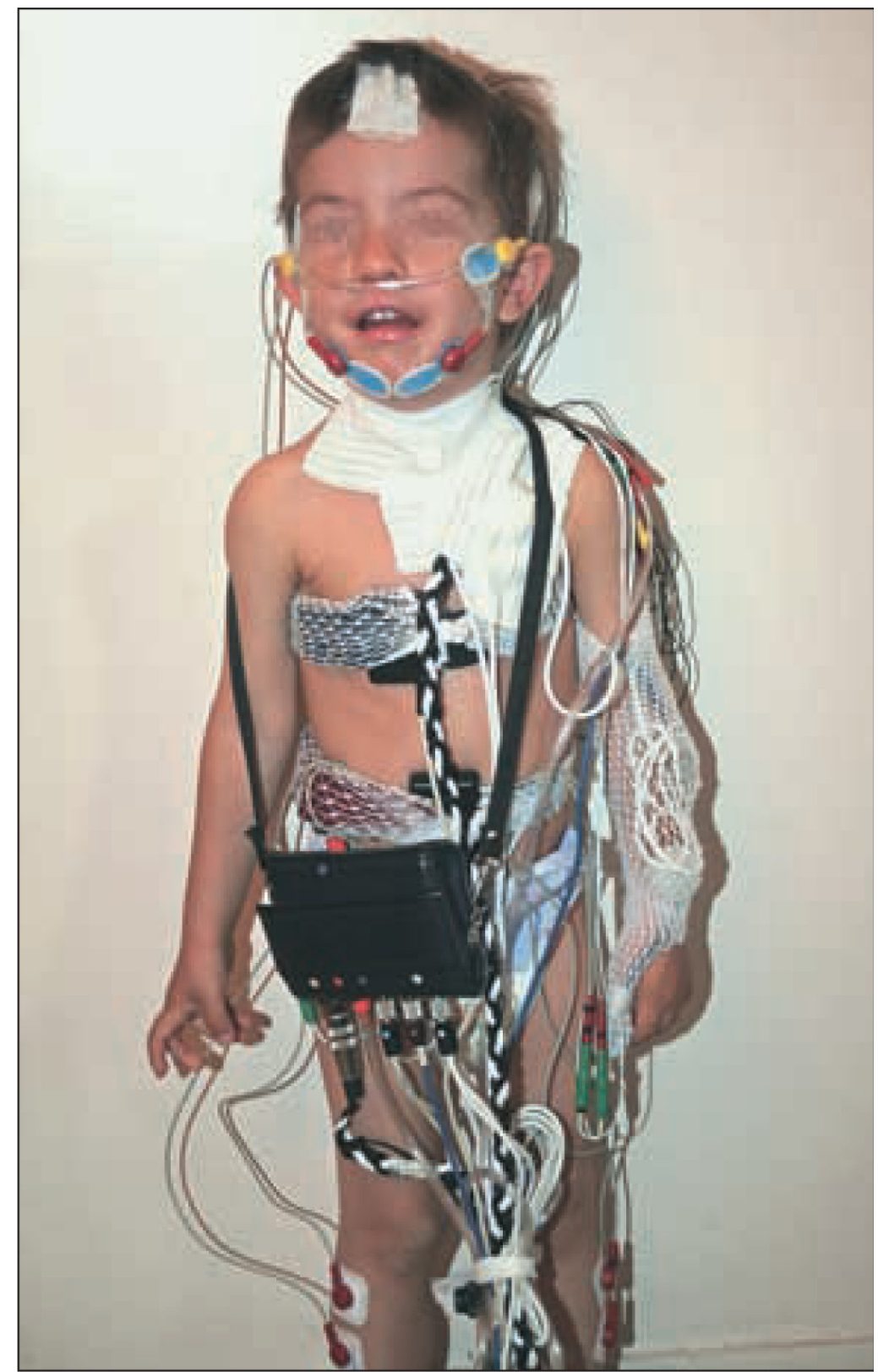

Figure 7

Sensor placement in a young patient before polysomnography in a sleep lab.

thoracic belts, a cervical microphone, and a pulse oxymeter. Examiners can distinguish obstructive apnea, in which the central nervous system control of breathing is not disturbed from apneas caused by disruption of the central nervous control system by measuring, ideally, esophageal pressure. If this is not possible an intercostal or diaphragmic electromyogram 
can be substituted for calculating respiratory effort. A nasal cannula can measure the level of carbon dioxide in expiration or a transcutaneous sensor can register the carbon dioxide blood level. Sometimes observers videotape sleeping patients to supplement the polysomnograph and record the precise sleeping behavior of the patient that may range from adjusting leg position to somnambulism.

All of these tests can help practitioners to make a diagnosis in cases of evident obstructive sleep apnea syndrome, making it possible to inaugurate immediate treatment, but if the examinations yield negative results they do not, in any way, rule out the possibility of OSAS developing later if the upper airways become more resistant to passage of air ${ }^{65}$.

The polysomnograph norms for children are not yet clearly defined and have changed with the passage of time, because the difficulty of comparing the results of different studies

\section{6 - CONCLUSION}

The discernment of symptoms, sometimes quite discrete, neglected, or misunderstood by parents, is indispensable for referral of a potential patient for a polysomnographic examination, which underscores the important role clinicians play and the critical nature of the intake histories they obtain. Orthodontists should under- have made it so far impossible to formulate normative limits.

According to the American Association of Sleep Medicine $(A A S M)^{3}$, apnea can be defined as a stoppage in respiration, or decrease in airflow of over $90 \%$ during two respiratory cycles and hypopnea can defined as:

- a decrease in air flow of 50\% during two respiratory cycles, associated with either a decrease in oxygen delivery equal to or over $30 \%$ during two respiratory cycles or a cortical mini-awakening;

- a decrease of $30 \%$ of air flow during two respiratory cycles or a decrease in oxygen supply greater than or equal to $4 \%$ or a cortical mini-awakening.

The AASM ${ }^{3,64,96}$ also states that an obstructive sleep apnea score greater than 1 per hour or Hypopnea Index greater than $1.5 / \mathrm{h}$ is probably abnormal and that Hypopnea Index higher than 3 to $5 / h$ is pathological in children.

stand that by virtue of the key observation positions they occupy they are integral members of the therapeutic team that elaborates a treatment plan after a diagnosis of OSAS has been made and then as participants in the restoration for afflicted subjects of physiological nasal breathing. 
1. Ali NJ et al. Sleep disordered breathing: effects of adenotonsillectomy on behaviour and psychological functioning. Eur J Pediatr 1996;155:56-62.

2. Ali NJ et al. Snoring, sleep disturbances and behaviour in 4-5year olds. Arch Dis Child 1993;68:360-6.

3. American Academy of Sleep Medecine. International classification of sleep disorders: diagnostic and coding manual $2^{\text {nd }}$ ed.Westchester IL: American Academy of Sleep Medecine, 2005.

4. Amin RS et al. Twenty-four-hour ambulatory blood pressure in children with sleepdisordered breathing. Am J Resp Crit Care Med.2004;169:950-56.

5. Amin RS et al. Left ventricular function in children with sleep-disordered breathing. Am J Cardiol 2005;95:801-4.

6. Amin RS et al. Left ventricular hypertrophy and abnormal ventricular geometry in children and adolescents with obstructive sleep apnea. Am J Respir Crit Care Med 2002;165:1395-99.

7. Arens R. et al. Magnetic resonance imaging of the upper airway structure of children with obstructive sleep apnea syndrome. Am J Respir Crit Care Med 2001;164:698-703.

8. Beebe DW et al. Neuropsychological effects of pediatric obstructive sleep apnea. J Int Neuropsychol Soc 2004;10:962-75.

9. Behlfelt $\mathrm{K}$ et al. Cranio-facial morphology in children with and without enlarged tonsils. Eur J Orthod 1990;12:233-43.

10. Blunden $S$ et al. Behavior and neurocognitive performance in children aged 5-10 years who snore compare to controls. J clin Exp Neuropsychol 2000;22:554-8.

11. Brietzke SE et al. Can history and physical examination reliably diagnose pediatric obstructive sleep apnea/hypopnes syndrome? A systematic review of the literature. Otolaryngol Head Neck Surg 2004;131:827-32.

12. Brooks JL. Enuresis in children with sleep apnea syndrome. J Pediatr 2003;142 515-18.

13. Brouilette R. A diagnostic approch to suspected obstructive sleep apnea in children. J Pediatrics 1984;105:10-14.

14. Chau KW et al. Clinical risk factors for obstructive sleep apnoea in children. Singapore Med J 2003;44:570-3.

15. Chervin RD et al. Correlates of respiratory cycled-related EEG changes in sleep disordered breathing. Sleep 2004:27;110-15.

16. Chervin RD et al. Inattention, hyperactivity and symptoms of sleep disordered breathing. Pediatrics 2002;109:449-56.

17. Chervin RD et al. Methode for detection of respiratory cycle-related EEG changes in sleep disordered breathing in children. Sleep 2004;27:110-15.

18. Chervin RD et al. Pediatric sleep questionnaire: prediction of sleep apnea and outcomes. Arch Otolaryngol Head Neck Surg 2007;133:216-22.

19. Chervin RD et al. Sleep disordered breathing, behaviour and cognition in children before and after adenotonsillectomy. Pediatrics 2006;117:e769-e778.

20. Chervin RD et al. Symptoms of sleep disorders, inattention, hyperactivity in children. Sleep 1997;20:1185-92.

21. Crabtree VM et al. Health-related quality of life and depressive symptoms in children with suspected sleep-disordered breathing. Sleep 2004;27:1131-8.

22. Donnelly LF. Upper airway motion depicted at cine MR imaging performed during sleep: comparaison between young patients with and those without obstructive sleep apnea. Radiology 2003;227:239-45.

23. Duman D et al. Impaired right ventricular function in adenotonsilar hypertrophy. Int $J$ Cardiovasc Imaging 2008;24:261-67. 
24. Enright Pl et al. Tucson Children's Assessment of Sleep Apnea Study. Blood pressure elevation associated with sleep-related breathing in a community sample of white and Hispanic children: The Tucson Children's Assessment of Sleep Apnea Study. Arch Pediatr Adolesc Med 2003;157:901-4.

25. Everett $A D$ et al. Failure to thrive due to obstructive sleep apnea. Clin Pediatr 1987;26:90-92.

26. Fitzpatrick MF. Effect of nasal or oral breathing route on upper airway resistance during sleep. Eur Respir J 2003;22:827-832.

27. Franco RA et al. First place-resident clinical science award 1999: quality of life for children with obstructive sleep apnea in children. Otolaryngol Head Neck Surg 2000;123:9-16.

28. Fregosi RF et al. Sleep disordered breathing, pharyngal size and soft tissue anatomy in children. J Appl Physiol 2003;95:2030-38.

29. Goldstein NA et al. Child behaviour and quality of life before and after tonsillectomy and adenoidectomy. Arch Otolaryngol Head Neck Surg 2002;128:770-5.

30. Goldstein NA et al. Clinical assessment of pediatric obstructive sleep apnea. Pediatrics 2004;114:33-43.

31. Gottlieb DJ et al. Sleep disordered breathing symptoms are associated with poorer cognitive functions in 5 year-old-children. J Pediatr 2004;145:458-64.

32. Gottlieb DJ. Symptoms of sleep-disordered breathing in 5-year old children are associated with slee- piness problem behaviors. Pediatrics 2003;112:870-7.

33. Gozal $D$ et al. Objective sleepiness mesures in pediatric obstructive sleep apnea. Pediatrics 2001;108: 693-7.

34. Gozal D. Sleep disordered breathing and school performance in children. Pediatrics 1998;102:616-20.

35. Guilleminault C. Children and nocturnal snoring-evaluation of the effects of sleep related respiratory resistive load and daytime functionning. Eur J Pediatr 1982;139:16571.

36. Guilleminault $\mathrm{C}$ et al. And if the polysomnography was faulty? Pediatr Pulmonol 1998;26:1-3.

37. Guilleminault $\mathrm{C}$ et al. Pediatric pbstructive sleep apnea syndrome. Arch Pediatr Adolesc Med 2005; 159:775-85.

38. Guilleminault C, Lee JH. Does benign "primary snoring" ever exist in children? Chest 2004;126:1396-98.

39. Guilleminault C. Areview of 50 children with obstructive sleep apnea syndrome. Lung 1981;159:275-87.

40. Guilleminault $C$ et al. Abnormal blood pressure in prepubertal children with sleepdisordered breathing. Pediatr Res 2004;55:76-84.

41. Guilleminault $C$ et al. Breathing patterns in prepubertal children with sleep related breathing disorders. Arch Pediatr Adolesc Med 2004;158:153-61.

42. Guilleminault $C$ et al. Sleep apnea in eight children. Pediatrics 1976;58:23-30.

43. Halbower AC et al. Childhood obstructive sleep apnea associates with neuropsychological deficits and neuronal brain injury. Plos Med 2006;3:e301.

44. Halbower AC et al. Childhood obstructive sleep-disordered breathing. Chest 2007;132:2030-41.

45. Hibbs AM. Prenatal and neonatal risk factors for sleep disordered breathing in schoolaged children born preterm. J Pediatr 2008;13:176-82.

46. Hill W. 1889 (British Medical Journal).

47. Isono $S$ et al. Comparaison of static mechanical properties of the passive pharynx between normal children and children with sleep disorder breathing. Am J Respir Crit Care Med 1998;157:1204-12.

48. Jeans WD et al. A longitudinal study of the growth of the nasopharynx and its contents in normal children. Br J Radiol 1981;54 117-21. 
49. Kaplan BJ et al. Sleep disturbance in preschool-aged hyperactive and nonhyperactive children. Pediatrics 1987;80:839-44.

50. Katz ES, D'Ambrosio CM. Pathaphysiology of pediatric obstructive sleep apnea. Proc Am Thorac Soc 2008;5:253-62.

51. Katz ES et al. Pulse transit time as a mesure of arousal and respiratory effort in children with sleep-disordered breathing. Pediatr Res 2003;53:580-88.

52. Kawashima $S$ et al. Cephalometric comparaisons of craniofacial and upper airway structures in young children with obstructive sleep apnea syndrome. Ear Nose Throat $\mathrm{J}$ 2000;79:499-506.

53. Kennedy JD. Reduced neurocognition in children who snore. Pediatr Pulmonol 2004;37:330-37.

54. Kheirandish-Gozal I et al. Reduced NREM sleep instability in children with sleep disordered breathing. Sleep 2007;30:450-7.

55. Kheirandish-Gozal $L$ et al. Elevated serum aminotransferase levels in children at risk for obstructive sleep apnea. Chest 2008;133:92-9.

56. Koyama $\mathrm{J}$ et al. Blood pressure in sleep disordered-breathing. Arch Dis Child 2003;88:139-42.

57. Kwok KL. BP and arterial distensibility in children with primary snoring. Chest 2003;123:1561-66.

58. Kwok KL et al. Cardiovascular changes in children with snoring and obstructive sleep apnoea. Ann Acad Med Singapore 2008;37:715-21.

59. Li HY et al. Sleep-disordered breathing in children. Chang Gung Med J 2009;32:247-57.

60. Lopes MC et al. Chronic snoring and sleep in children: a demonstration of sleep disruption. Pediatrics 2006;118:e741-e746.

61. Lumeng JC et al. Epidemiology of pediatric obstructive sleep apnea. Proc Am Thorac Soc. 2008;242-52.

62. Marcus CL et al. Determinants of growth in children with the obstructive sleep apnea syndrome. J Pediatr 1994;125:556-62.

63. Marcus CL et al. Blood pressure in children with obstructive sleep apnea. Am J Resp Crit Care Med 1998;157:1098-1103.

64. Marcus CL et al. Normal Polysomnographic Values for children and adolescents. Am rev Resp Dis1992;146:1235-39.

65. Marcus CL. Sleep disordered-breathing in children. Am J Respir Crit Care Med 2001;164:16-30.

66. Melendres MC et al. Daytime sleepiness and hyperactivity in children with suspected sleep-disordered breathing. Pediatrics 2004;114:768-75.

67. Mitchell RB et al. Quality of life after adenotonsillectomy for obstructive sleep apnea in children. Arch Otlolaryngol Head Neck Surg 2004;130:190-94.

68. Mitchell RB et al. Behavioral changes in children with mild sleep-disordered breathing or obstructive sleep apnea after adenotonsillectomy laryngoscope 2007;117:1685-8.

69. Monahan KJ et al. Utility of noninvasive pharyngometry in epidemic studies of childhood sleep-disordred breathing. Am J Respir Crit Care Med 2002;165:1499-1503.

70. Montgomery-Downs HE et al. Snoring in preschoolers: association with sleepiness, ethnicity, and learning. Clin Pediatr 2003;42:719-26.

71. Moyer CA et al. Quality of life in obstructive sleep apnea: a systematic review of the literature. Sleep Med 2001;2:477-91.

72. O'Brien LM et al. Neurobehavioral correlates of sleep disordered breathing in children. J Sleep Res 2004;13:165-72.

73. O'Brien LM et al. Sleep in children with attention deficit/hyperactivity disorder. Minerva Pediatr 2004; 56:585-601.

74. O'Brien L et al. Neurobehavioral implications of habitual snoring in children. Pediatrics 2004;114:44-9.

75. Osler W. The principles and practices of Medecine. New York Appletown and Co 1892;335-339. 
76. Owens $\mathrm{J}$ et al. Sleep and daytime behaviour in children with obstructive sleep apnea and behavioural sleep disorders. Pediatrics 1998;102:1178-82.

77. Pillar G. An autonomic ambulatory device for detection of AASM defined arousal from sleep: the WP100. Sleep med 2003;4:207-12.

78. Pillar G. Autonomic arousal index; an automated detection based on peripheral arterial tonometry. Sleep 2002;25:543-9.

79. Poyares D. EEG spectral power and pulse transit time in UARS and mild OSAS Subjects. Clin Neurophysiol 2002;113:1598-1606.

80. Redline $\mathrm{S}$ et al. Association between metabolic syndrome and sleep-disordered breathing in adolescents. Am J resp Crit care med 2007;176:401-8.

81. Redline $\mathrm{S}$ et al. Risk factors for sleep-disordered breathing in children. Am J Respir Crit Care Med.1999;159:1527-32.

82. Reuveni $\mathrm{H}$ et al. Health care services utilization in children with obstructive sleep apnea syndrome. Pediatrics 2002;110:68-72.

83. Rhodes SK et al. Neurocognitive deficits in morbidly obese children with obstructive sleep apnea. J Pediatr 1995;127:741-4.

84. Rosen CL et al. Prevalence and risk factors for sleep disordered breathing in 8-to11year-old children:association with race and prematurity. J Pediatr 2003;142:383-9.

85. Rosen CL et al. Health-related quality of life and sleep-disordered breathing in children. Sleep 2002;25:657-66.

86. Sans Capdevila O et al. Pediatric obstructive sleep apnea:complications, management, and long term outcomes. Proc Am Thorac Soc 2008;5:274-82.

87. SFRMS. Procédure de réalisation et d'analyse d'un enregistrement du sommeil chez I'enfant. Franco P. et Challamel Marie-Josephe. Recommandations SFRMS de bonnes pratiques cliniques $\mathrm{N}^{\circ} 8(\mathrm{R} 8)$.

88. Stein MA et al. Sleep and behaviour problems in school-aged children. Pediatrics 2001;107:e60.

89. Tarasiuk et al. Eleveted morbidity and health care use in children with obstructive sleep apnea syndrome. Am J Resp Crit Care Med 2007;175:55-61.

90. Tauman $\mathrm{R}$ et al. Peripheral arteriel tonometry events and electroencephalographic events in children. Sleep 2004;27502-506.

91. Tauman R. et al. Sleep pressure score: a new index of sleep disruption in snoring children. Sleep 2004;27:274-8.

92. Technical report: diagnosis and management of childhood obstructive sleep apnea syndrome. Pediatrics 2002;109:e69.

93. Urschitz MS et al. Habitual snoring, intermittent hypoxia, and impair behaviour in primary school children. Pediatrics 2004;114:1041-8.

94. Weissbluth $M$ et al. Signs of airway obstruction during sleep and behavioural, developpemental, and academic problemes. J Dev Behav Pediatr 1983;4:119-21.

95. Wilson SL. Upper airway patency in the human infant: influence of airway pressure and posture. J Appl Phy 1980;48:500-504.

96. Witmans MB et al. Obstructive hypopneas in children and adolescents:normal values. Am J Respir Crit Care Med 2003;168:1540.

97. Xu Z et al. Clinical evaluation in predicting childhood obstructive sleep apnea. Chest 2006;130:1765-71.

98. Zintsaras E et al. Sleep-disordered breathing and blood pressure in children. A metaanalysis. Arch Pediatr Adolesc Med 2007;161:172-8. 